\title{
Impact of strength of fault current path on the operation of decoupled double synchronous reference frame - phase locked loop
}

\author{
A. S. Mäkinen, H. Tuusa \\ Department of Electrical Energy Engineering \\ Tampere University of Technology \\ Korkeakoulunkatu 3, FI-33101, Tampere, Finland \\ Phone:+358401981522, e-mail: anssi.makinen@tut.fi
}

\begin{abstract}
This paper studies the performance of decoupled double synchronous reference frame - phase locked loop (DDSRF-PLL) synchronizing method during grid fault. The study is carried out using Matlab/Simulink. The contribution of the paper is to reveal that if the DDSRF-PLL proposed in many papers is used, the control system of network side converter (NSC) may become unstable during a symmetrical grid fault. The instability problem appears only when certain tuning parameters of DDSRF-PLL are used and the fault current path is weak. Thus, the problem may not be easily detected. This paper emphasizes that it is mandatory to use PI-controller with integrator antiwindup in the loop filter of DDSRF-PLL. In addition, the impact of angular frequency limitation range on the fault ride through performance is evaluated with comparative simulations.
\end{abstract}

\section{Key words}

Wind turbine, synchronization, DDSRF-PLL, integrator anti-windup, PI-controller

\section{Introduction}

The amount of electricity generated using wind turbines (WT) has increased dramatically in recent years. According to World Wind Energy Association (WWEA), the worldwide WT capacity at the end of year 2011 was 239 GW covering $3 \%$ of the world's electricity demand. [1] In the past, due to the low penetration of grid connected WTs the operation of WTs did not have great impact on the operation of the utility grid. Nowadays, the penetration level of the WTs has increased in many areas and the operation of WTs should be designed so that the stable operation of the power system is not endangered in any circumstances due to the WT connection. Thus, the power system operators have created grid codes which determine how WTs should operate under different grid conditions. [2] In order to fulfil the grid codes, WTs should be able to control its active and reactive power output as well as to stay in operation during grid disturbances.

The technical challenges above are strongly related to the control system design of the WT frequency converter. The converter consists of a generator side converter (GSC) which controls the generator speed and a network side converter (NSC) which controls the converter DC-link voltage and the reactive power output.

The most important task for WT is to generate electrical power to the network with minimized losses. This task is fulfilled when the WT feeds only fundamental frequency positive sequence currents into the network. Because the control system of the vector controlled NSC is usually realized in a synchronous reference frame, the fundamental frequency positive sequence currents can be generated if the angle of the network voltage fundamental frequency positive sequence component is somehow detected. Moreover, the currents can be divided into active and reactive current components which can be controlled independently from each other. Thus, the active and the reactive power output of the WT can be controlled as required by the grid codes.

In this study, the decoupled double synchronous reference frame - phase locked loop (DDSRF-PLL) is used to provide the angle for the control system of NSC. It is shown in this paper that the WT may become unstable during a symmetrical grid fault if the DDSRFPLL proposed in many papers is used. [3][4][5][6] The instability problem is very harmful because it appears only when the WT with certain tuning parameters of DDSRF-PLL is connected into a weak network. Thus, the problem may not be detected. This paper underlines that it is obligatory to use PI-controller with integrator antiwindup in the loop filter (PI-controller) of DDSRF-PLL. In addition, the impact of angular frequency limitation range on the fault ride through performance is evaluated with comparative simulations.

\section{DDSRF-PLL}

The DDSRF-PLL consists of a decoupling network and phase locked loop operating on synchronous reference frame (SRF-PLL). The decoupling network provides positive and negative sequence components from the 
input voltage vector. The synchronization to the positive sequence component of the grid voltage is achieved when the voltage positive sequence q-component is controlled to zero. This is done using SRF-PLL.

\section{A. Decoupling network}

The unbalanced grid voltage vector $\underline{u}_{\alpha \beta}$ can be expressed in stationary reference frame as follows: [5]

$$
\underline{u}_{\alpha \beta}=\left[\begin{array}{c}
u_{\alpha} \\
u_{\beta}
\end{array}\right]=U^{+}\left[\begin{array}{c}
\cos \left(\omega t+\varphi^{+}\right) \\
\sin \left(\omega t+\varphi^{+}\right)
\end{array}\right]+U^{-}\left[\begin{array}{c}
\cos \left(-\omega t+\varphi^{-}\right) \\
\sin \left(-\omega t+\varphi^{-}\right)
\end{array}\right]
$$

where $U$ is peak value of the phase voltage, $\omega$ is angular frequency of the grid and $\varphi$ is initial angle. Superscripts + and - correspond to the positive and negative sequence references. It is assumed that the positive sequence reference frame is rotating synchronously with the fundamental frequency positive sequence grid voltage component. Thus, $\theta_{\text {sync }}=\omega t$. The positive and negative sequence components can be expressed in synchronous dqreference frame using angle $\theta_{\text {sync }}$ which is the output of the SRF-PLL. [5]

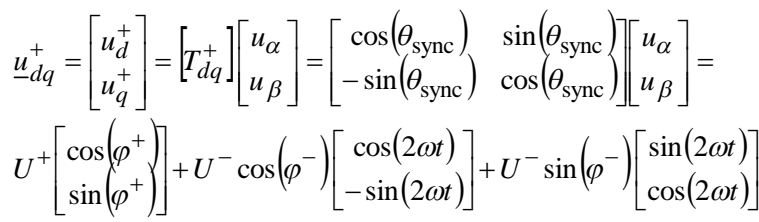

$\underline{u}_{\mathrm{dq}}^{-}=\left[\begin{array}{c}u_{\mathrm{d}}^{-} \\ u_{\mathrm{q}}^{-}\end{array}\right]=\left[T_{\mathrm{dq}}^{-}\right]\left[\begin{array}{l}u_{\alpha} \\ u_{\beta}\end{array}\right]=$

$U^{-}\left[\begin{array}{c}\cos \left(\varphi^{-}\right. \\ \sin \left(\varphi^{-}\right.\end{array}\right]+U^{+} \cos \left(\varphi^{+}\right)\left[\begin{array}{c}\cos (2 \omega t) \\ \sin (2 \omega t)\end{array}\right]+U^{+} \sin \left(\varphi^{+}\right)\left[\begin{array}{c}-\sin (2 \omega t) \\ \cos (2 \omega t)\end{array}\right]$

The left side terms in Equations (2) and (3) are DC-values and right side terms are AC-values. The DC-values are solved in order to distinguish the positive and the negative sequence components from the grid voltage: [5]

$$
\begin{aligned}
& U^{+}\left[\begin{array}{l}
\cos \left(\varphi^{+}\right) \\
\sin \left(\varphi^{+}\right)
\end{array}\right]=\left[\begin{array}{l}
U_{\mathrm{d}}^{+} \\
U_{\mathrm{q}}^{+}
\end{array}\right]= \\
& {\left[\begin{array}{c}
u_{\mathrm{d}}^{+} \\
u_{\mathrm{q}}^{+}
\end{array}\right]-U^{-} \cos \left(\varphi^{-}\right)\left[\begin{array}{c}
\cos (2 \omega t) \\
-\sin (2 \omega t)
\end{array}\right]-U^{-} \sin \left(\varphi^{-}\right)\left[\begin{array}{l}
\sin (2 \omega t) \\
\cos (2 \omega t)
\end{array}\right]} \\
& U^{-}\left[\begin{array}{l}
\cos \left(\varphi^{-}\right. \\
\sin \left(\varphi^{-}\right.
\end{array}\right)=\left[\begin{array}{c}
U_{\mathrm{d}}^{-} \\
U_{\mathrm{q}}^{-}
\end{array}\right]= \\
& {\left[\begin{array}{c}
u_{\mathrm{d}}^{-} \\
u_{\mathrm{q}}^{-}
\end{array}\right]-U^{+} \cos \left(\varphi^{+}\right)\left[\begin{array}{c}
\cos (2 \omega t) \\
\sin (2 \omega t)
\end{array}\right]-U^{+} \sin \left(\varphi^{+}\right)\left[\begin{array}{c}
-\sin (2 \omega t) \\
\cos (2 \omega t)
\end{array}\right]}
\end{aligned}
$$

The decoupling network based on (4) and (5) and shown in Fig. 1 is used to cancel AC components from positive and negative sequence reference frames. The block LPF represents a simple first order low-pass filter with cut-off frequency of $\omega_{\mathrm{f}}$ : [5]

$$
\operatorname{LPF}(s)=\frac{\omega_{\mathrm{f}}}{s+\omega_{\mathrm{f}}}
$$

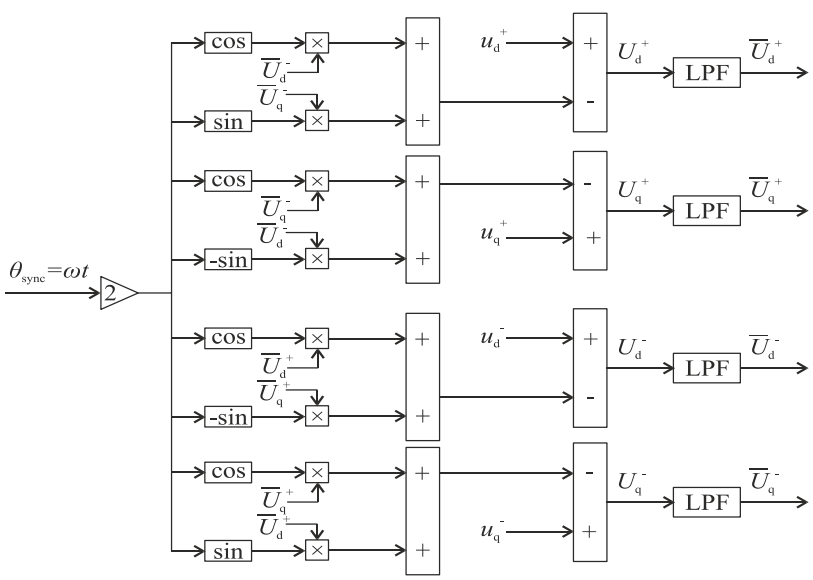

Fig. 1. Decoupling network.

The decoupling network provides positive and negative sequence components from the input voltage vector. Thus, it is possible to synchronize the control system of the NSC to the grid voltage positive sequence component which is desired in wind turbine applications. The synchronization to the positive sequence component of the grid voltage is achieved when the positive sequence q-axis voltage component $U_{\mathrm{q}}^{+}$is zero. In that case, the initial phase angle $\varphi^{+}$is zero and the positive sequence voltage component is aligned to $\mathrm{d}^{+}$-axis rotating with angular speed of $\omega$. The angle of positive sequence voltage component $\theta_{\text {sync }}$ is obtained using SRF-PLL.

\section{B. SRF-PLL}

The balanced grid voltage vector in stationary reference frame can be expressed as follows: [5]

$\underline{u}_{\alpha \beta}=\left[\begin{array}{c}u_{\alpha} \\ u_{\beta}\end{array}\right]=U\left[\begin{array}{c}\cos (\omega t) \\ \sin (\omega t)\end{array}\right]$

The (7) in synchronous reference frame rotating with angle provided by the synchronization system $\theta_{\text {sync }}$ is: [5]

$\left[\begin{array}{l}u_{\mathrm{d}} \\ u_{\mathrm{q}}\end{array}\right]=\left[\begin{array}{cc}\cos \theta_{\text {sync }} & \sin \theta_{\text {sync }} \\ -\sin \theta_{\text {sync }} & \cos \theta_{\text {sync }}\end{array}\right]\left[\begin{array}{l}u_{\alpha} \\ u_{\beta}\end{array}\right]=U\left[\begin{array}{c}\cos \left(\omega t-\theta_{\text {sync }}\right) \\ \sin \left(\omega t-\theta_{\text {sync }}\right)\end{array}\right]$

The voltage component of interest in (8) is the $u_{\mathrm{q}}$ since the purpose of the control system is to regulate the voltage q-component to zero. Due to the sinusoidal function in (8) the system under consideration is nonlinear. However, when the phase difference $\theta-\theta_{\text {sync }}$ is small the sinusoidal term behaves almost linearly. [5] The block diagram of linearized SRF-PLL is shown in Fig. 2 and the closed loop transfer function is based on:

$$
H_{\mathrm{cl}}(s)=\frac{\theta_{\mathrm{PLL}}}{\theta}=\frac{k_{\mathrm{PLL}} s+\frac{k_{\mathrm{PLL}}}{T_{\mathrm{i}}}}{s^{2}+k_{\mathrm{PLL}} s+\frac{k_{\mathrm{PLL}}}{T_{\mathrm{i}}}}=\frac{2 \varsigma \omega_{\mathrm{n}} s+\omega_{\mathrm{n}}^{2}}{\mathrm{~s}^{2}+2 \varsigma \omega_{\mathrm{n}} s+\omega_{\mathrm{n}}^{2}}
$$

where $k_{\mathrm{PLL}}=-U^{*} k_{\mathrm{LF}}$ represents the PLL gain, $k_{\mathrm{LF}}$ is loop filter gain, $T_{\mathrm{i}}$ is integration time, $\omega_{\mathrm{n}}$ is undamped natural frequency and $\zeta$ is damping factor. The feed forward term $\omega_{\mathrm{ff}}$ is used to set the frequency near the final value in order to accelerate start-up process. The angular position $\theta_{\text {sync }}$ of the rotating reference frame is attained after integration of $\omega_{\text {sync. [7] }}$ 


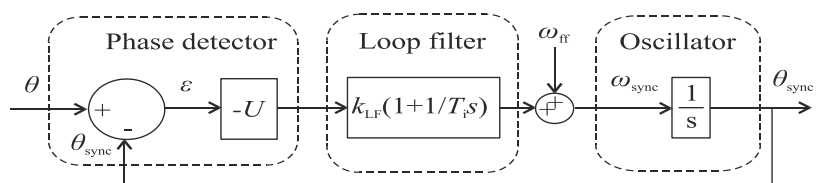

Fig. 2. Linearized block diagram of the SRF-PLL.

\section{DDSRF-PLL}

The DDSRF-PLL is a combination of decoupling network and SRF-PLL. The block diagram of the DDSRF-PLL is shown in Fig. 3. [3][4][5][6]

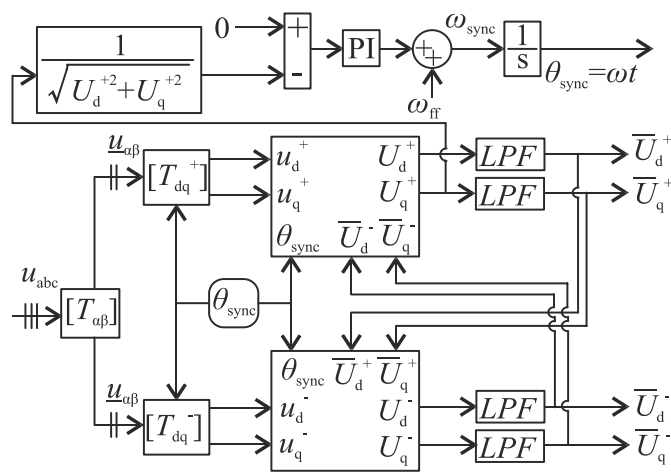

Fig. 3. The block diagram of DDSRF-PLL.

As can be seen from Fig. 2 the gain of the system depends on the loop filter parameters as well as input voltage magnitude $U$. If the input voltage drops, also the PLL gain falls down. [7] Thus, the regulated value $U_{\mathrm{q}}^{+}$is actively normalized to the amplitude of the positive sequence component of the grid voltage vector. The parameters used in DDSRF-PLL are: $\omega_{\mathrm{f}}=2 * \pi * 50 / \operatorname{sqrt}(2), k_{\mathrm{LF}}=-177.7, T_{\mathrm{i}}=$ $0.0113 \mathrm{~s}$. The parameters are often expressed in terms of $\zeta$ and $\omega_{\mathrm{n}}$ which are: $\zeta=\operatorname{sqrt}(2), \omega_{\mathrm{n}}=2 * \pi * 20 .[5][8]$

\section{Frequency limitation and integrator anti-windup}

After the grid voltage dip the grid angle may change rapidly causing significant error measure $\varepsilon$ in Fig. 2. The loop filter, which is typically a PI-controller, aims to regulate the $\varepsilon$ to zero. As a result of the PI controller actions, the loop filter output $\omega_{\text {sync }}$ may deviate significantly from the grid voltage frequency. The consequence is increased amount of harmonics in currents fed into the network. Due to the fact that the grid frequency is a reasonably stable variable it is vice to limit the $\omega_{\text {sync }}$. Another problem is the windup of the integrator part of the controller. [9] If the sign of significant $\varepsilon$ remains unchanged for a reasonable time the output value of the integrator may become very large causing remarkable deviation of $\omega_{\text {sync }}$ from the grid frequency. If the $\omega_{\text {sync }}$ is limited the saturation of $\omega_{\text {sync }}$ continues for a long time due to the windup. Thus, it is important to stop the integration when the $\omega_{\text {sync }}$ saturates. This is called as integrator anti-windup and it can be realised using SRFPLL structure shown in Fig. 4.

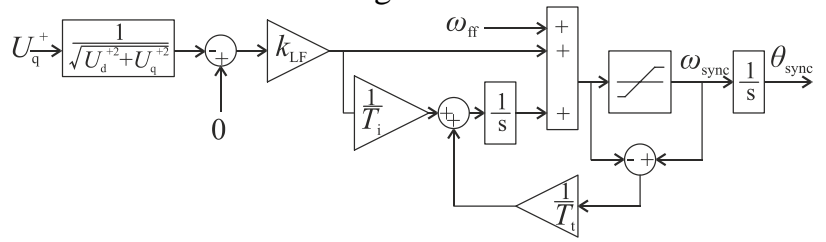

Fig. 4. SRF-PLL with integrator anti-windup. [9]
Generally, the anti-windup tracking time constant $T_{\mathrm{t}}$ should be small enough to prevent the integrator from saturation. However, very small value of $T_{\mathrm{t}}$ increases the anti-windup gain significantly which decreases the effect of the loop filter integral controller. Thus, the performance of the loop filter may decrease. In [9], it is suggested that the $T_{\mathrm{t}}$ should be smaller than $T_{\mathrm{i}}$.

\section{Simulation model}

The network model used in the study is shown in Fig. 5. The $110 \mathrm{kV}$ transmission network consists of two parallel feeders. The feeder 1 represents weak feeder having much greater impedance compared to feeder 2 . The feeder 1 impedance values including transformer TF1 are chosen so that when circuit breakers $C b_{\mathrm{f} 21}$ and $C b_{\mathrm{f} 22}$ are opened the feeder impedance equals to the impedance found in real Finnish network. The feeder 2 impedances have been similarly measured from the real Finnish grid.

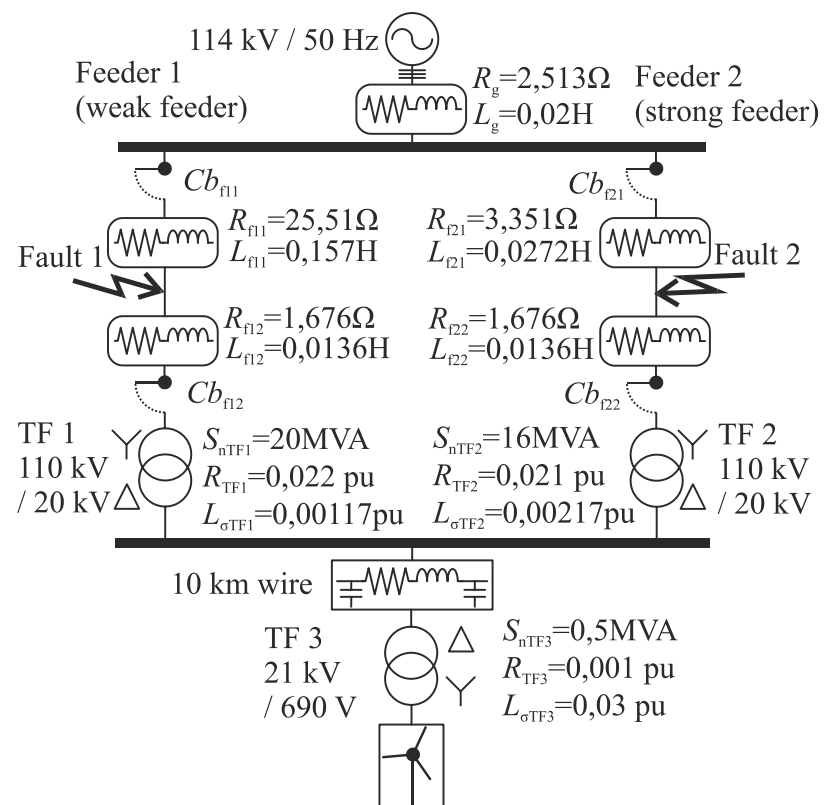

Fig. 5. Network model with used parameters.

The wind turbine system model including the control system of the NSC is shown in Fig. 6. The target of this study is to analyse the synchronization of the WT system. Hence, it is unnecessary to model the mechanical parts of the WT in detail because the mechanical time constants are much greater than time constants related to synchronization. Thus, the mechanical parts, generator and GSC are modelled as a current source $i_{\mathrm{WT}}$ in the DClink of the frequency converter where the generated electrical power $p_{\text {gen }}$ is controllable. The value for $i_{\mathrm{WT}}$ is calculated from:

$$
i_{\mathrm{WT}}=\frac{p_{\text {gen }}}{u_{\mathrm{dc}}}
$$

where $u_{\mathrm{dc}}$ is the DC-link voltage. The braking chopper for DC-link overvoltage protection is modelled in the DClink of the frequency converter. The switch activating the chopper is closed when the DC-link voltage increases above $1250 \mathrm{~V}$ and the surplus energy is dissipated in the resistance $R_{\mathrm{dc}}$. 
The vector control of NSC is done in the reference frame synchronized to the connection point voltage $u_{\text {sync }}$ using DDSRF-PLL. The phase angle of the fundamental frequency component of the voltage is the output of the block Sync. The aim of the dc-link voltage controller is to maintain constant dc-link voltage, thereby ensuring that the generated active power $p_{\text {gen }}$ in (10) is fed into the network. The output of the dc-link voltage controller is the $\mathrm{d}$-component of the converter current $i_{\mathrm{Lld}}$. Reactive power controller outputs the reference of q-axis component of the grid side current $i_{\mathrm{L} 1, \mathrm{q}}{ }^{*}$. The reference value for the connection point instantaneous reactive power $q^{*}$ is zero in the study. During a voltage dip, the reference for $i_{\mathrm{Llq}}{ }^{*}$ depends on the network voltage magnitude $\left|\underline{u}_{\text {sync }}\right|$. If the voltage is lower than nominal value, reactive power is injected to the network to support the network voltage. The calculation of instantaneous reactive power $q$ is performed in the pq-calculation block. The reference currents $i_{\mathrm{L} 1 \mathrm{~d}}{ }^{*}$ and $i_{\mathrm{L} 1 \mathrm{q}}{ }^{*}$ are compared to the measured values and the errors are fed to the current controllers. The outputs of the current controllers are the voltage components over LCLfilter inductors $u_{\mathrm{Ld}}{ }^{*}$ and $u_{\mathrm{Lq}}{ }^{*}$. Removing the cross-coupling terms and with the help of the measured connection point voltage components $u_{\text {sync, } d}$ and $u_{\text {sync, }}$, the NSC voltage reference components $u_{\mathrm{conv}, \mathrm{d}}{ }^{*}$ and $u_{\mathrm{conv}, \mathrm{q}}{ }^{*}$ can be calculated.

The switching action is not taken into account in this study and the NSC is assumed to produce the reference voltage $\underline{u}_{\mathrm{NSC}}$ ideally. However, the design of the LCL-filter was based on the switching frequency $f_{\mathrm{sw}}$ of $3.6 \mathrm{kHz}$. The resonance frequency of the filter $f_{\text {res }}$ is $1072 \mathrm{~Hz}$ when the transformer inductance $L_{\sigma \mathrm{TF} 3}$ is taken into account. [10]

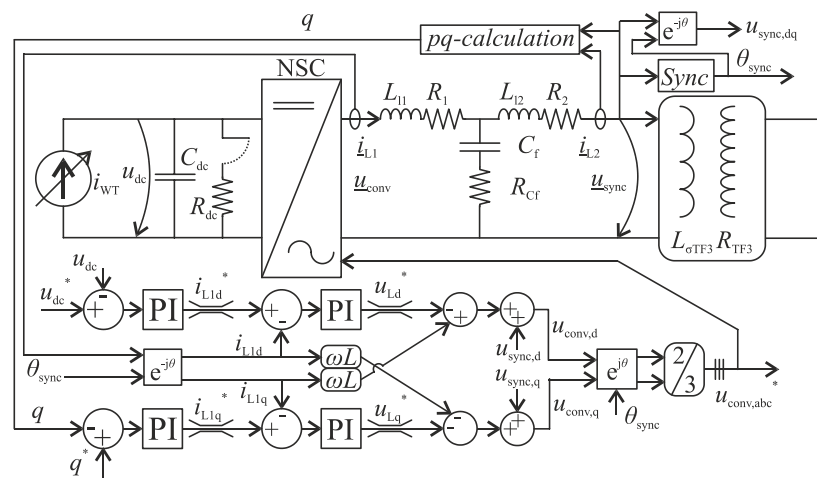

Fig. 6. Wind turbine system model and control system of NSC.

Table I. - LCL-filter and NSC parameters

\begin{tabular}{|c|c|c|c|c|c|c|}
\hline$L_{11}=300 \mu \mathrm{H}$ & \multicolumn{2}{|c|}{$L_{12}=83 \mu \mathrm{H}$} & \multicolumn{2}{|c|}{$R_{1}=2.4 \mathrm{~m} \Omega$} & $R_{2}=1 \mathrm{~m} \Omega$ & $C_{\mathrm{f}}=0.2 \mathrm{~m} \Omega$ \\
\hline$R_{\mathrm{Cf}}=0.25 \Omega$ & & $1100 \mathrm{~V}$ & & $22 \mathrm{mF}$ & $R_{\mathrm{dc}}=2 \Omega$ & \\
\hline \multicolumn{7}{|c|}{ Table II. - Control parameters } \\
\hline \multicolumn{2}{|l|}{ Controller } & \multicolumn{2}{|c|}{ Current } & \multicolumn{2}{|c|}{ DC-link } & $\begin{array}{l}\text { Reactive } \\
\text { power }\end{array}$ \\
\hline \multicolumn{2}{|l|}{ Gain } & \multicolumn{2}{|l|}{$k_{\mathrm{i}}=0.6$} & \multicolumn{2}{|c|}{$k_{\mathrm{udc}}=4$} & $k_{\mathrm{q}}=-0.45$ \\
\hline \multicolumn{2}{|c|}{ Integration time } & \multicolumn{2}{|c|}{$T_{\mathrm{i}}=3 \mathrm{~ms}$} & \multicolumn{2}{|c|}{$T_{\mathrm{i}_{\mathrm{udc}}}=25 \mathrm{~ms}$} & $T_{\mathrm{i}_{\mathrm{q}}}=40 \mathrm{~ms}$ \\
\hline \multicolumn{2}{|c|}{ Sampling time } & \multicolumn{2}{|c|}{$T_{\mathrm{s}_{\mathrm{i}}}=100 \mu \mathrm{s}$} & \multicolumn{2}{|c|}{$T_{\mathrm{s} \text { udc }}=100 \mu \mathrm{s}$} & $T_{\mathrm{S}_{\mathrm{q}} \mathrm{q}}=100 \mu \mathrm{s}$ \\
\hline \multicolumn{2}{|l|}{ Limitation } & \multicolumn{2}{|c|}{$\begin{array}{l}\left|u_{\text {Lmax }}\right|= \\
100 \mathrm{~V}\end{array}$} & \multicolumn{2}{|c|}{$\begin{array}{l}\left|i_{\text {Lldmax }}\right|= \\
900 \mathrm{~A}\end{array}$} & $\begin{array}{l}\left|i_{\mathrm{L} 1 \mathrm{qmax}}\right|= \\
700 \mathrm{~A}\end{array}$ \\
\hline
\end{tabular}

The used parameter values for the LCL-filter and NSC are shown in Table I. The controller parameters are expressed in Table II. The d- and q-axis current controllers use same parameters. It should be noted that limit values are vector limit values i.e. peak value of the phase quantity.

\section{Simulation case}

In the simulations two fault points (Fault 1 and Fault 2) are used. It is assumed that the network protection is based on distance protection with the following operation procedure. The three phase fault occurs in point Fault 1 of Fig. 5 at $0.3 \mathrm{~s}$. After $200 \mathrm{~ms}$ from the beginning of the fault at $0.5 \mathrm{~s}$ the circuit breaker $C b_{\mathrm{f} 12}$ opens and the WT currents flow through strong feeder 2 and through circuit breaker $C b_{\mathrm{f} 11}$. After $300 \mathrm{~ms}$ from the fault beginning at $0.6 \mathrm{~s}$ the $C b_{\mathrm{f} 11}$ opens and the fault is cleared from the WT viewpoint. [11] When the fault point is Fault 2 same process is applied but circuit breakers $C b_{\mathrm{f} 21}$ and $C b_{\mathrm{f} 22}$ operates.

The control principle of NSC is chosen such that the reactive power is prioritized during the grid fault. Thus, the reference of NSC current q-component is increased to $591 \mathrm{~A}$ and the current $i_{\mathrm{WT}}$ in (10) is set to zero during the fault.

\section{A. Three-phase fault in feeder 1}

The connection point voltages are shown in Fig. 7a. After first transients the converter current waveforms become sinusoidal as shown in Fig. 7b. The transients appear due to the phase angle jump of the grid voltage which is not completely filtered out by the DDSRF-PLL as can be seen from the Fig. 7c, which has different time scaling compared to other Figs. 7 for the sake of clarity. The angular frequency of the PLL shows significant oscillations after the fault as shown in Fig. 7d. However, it takes only $19.5 \mathrm{~ms}$ for the frequency to settle down within $2 \%$ of the steady state value.

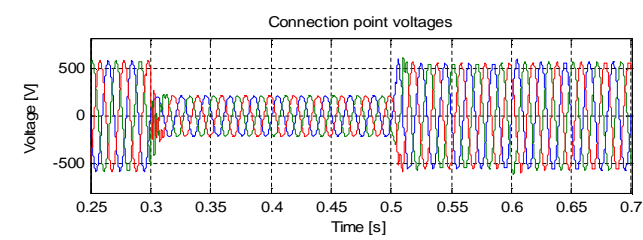

Fig. 7. a) Connection point voltages.

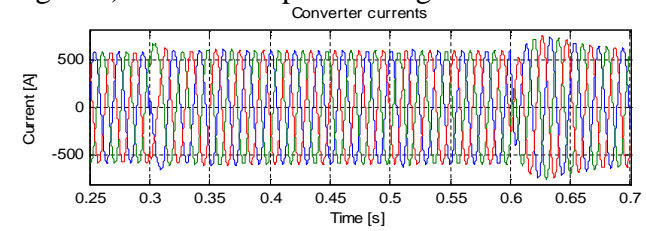

Fig. 7. b) Converter currents.

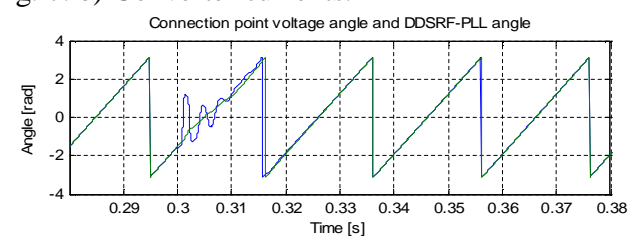

Fig. 7. c) Connection point and DDSRF-PLL angle.

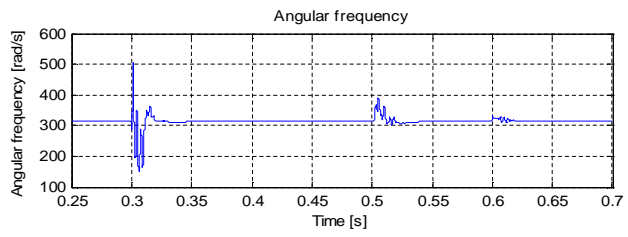

Fig. 7. d) Angular frequency of the DDSRF-PLL. 


\section{B. Three-phase fault in feeder 2}

Next, three-phase fault on the fault point 2 is simulated. The path for fault current is now through feeder 1 which is significantly weaker than the feeder 2 . The connection point voltages and converter currents are shown in Fig. 8a and $8 \mathrm{~b}$, respectively. It should be noticed that a significant DC-component appears on the converter currents. This is not tolerable because it overstress the network components, especially the WT transformer.

Theoretically, symmetrical voltage dip does not generate a negative sequence component at fundamental frequency. However, the output of the negative sequence component calculated by the decoupling network is not zero during the transients. Thus, the calculated nonzero negative sequence component modifies the value of the calculated positive sequence voltage q-component. If the frequency is not limited the integration part of the PI controller shown in Fig. 8c reaches a high negative value. As a result, the angular frequency of DDSRF-PLL, shown in Fig. 8d, drops near zero. The angle fed to the control system of NSC is the integral of the angular frequency. Thus, the angle shown in Fig. 8e does not change linearly and during near zero angular speed the angle remains nearly constant. Hence, the converter currents contain the DC-component.

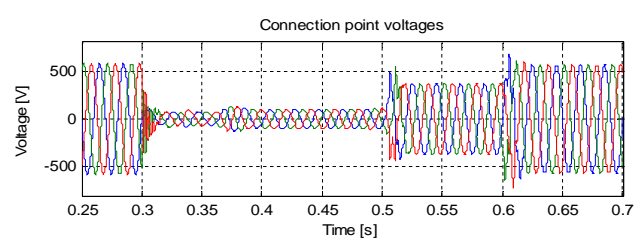

Fig. 8. a) Connection point voltages.

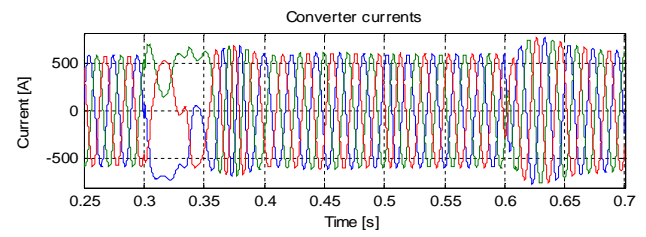

Fig. 8. b) Converter currents

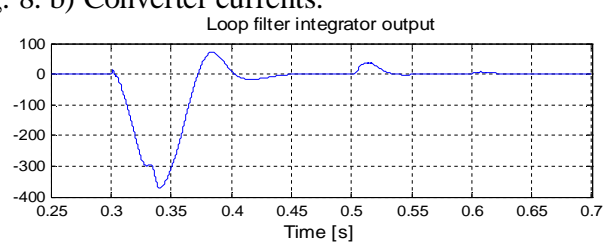

Fig. 8. c) Output of the loop filter integrator.

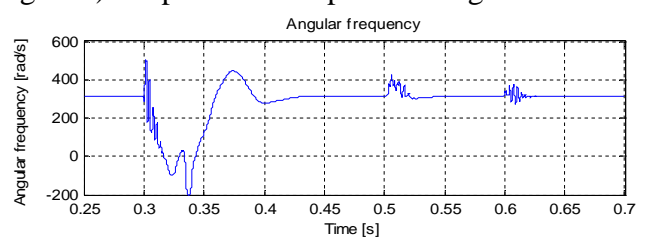

Fig. 8. d) Angular frequency of the DDSRF-PLL.

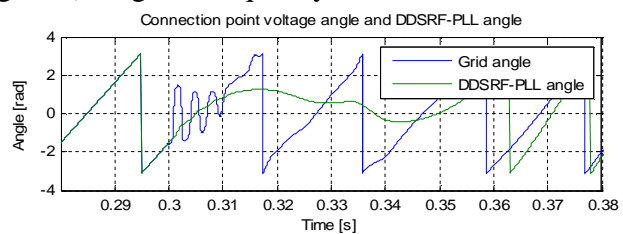

Fig. 8. e) Connection point and DDSRF-PLL angle.

\section{Impact of anti-windup and frequency limitation}

The frequency limitation with integrator anti-windup function of Fig. 4 is added to the DDSRF-PLL loop filter in order to avoid the problems discussed above. The same three-phase fault in feeder 2 is simulated using 5 different frequency limits and 2 different anti-windup time constants. The purpose is to find optimal limits for frequency. The simulation results are collected to the Table III.

The settling time of the first transient is defined as the time measured from the start time of the fault to the time in which the frequency will stay within $2 \%$ of the steady state value. The fundamental frequency negative sequence component and harmonic components from the $2^{\text {nd }}$ to the $20^{\text {th }}$ from the converter current are integrated (summed) in order to measure the quality of the generated current. This harmonic integral is calculated from time span of $0.3-0.7 \mathrm{~s}$. The converter currents contain less of harmonics throughout the transient fault when the harmonic integral value is small.

Table III. - Impact of anti-windup and frequency limitation

\begin{tabular}{|l|l|l|l|}
\hline Frequency limit & $\begin{array}{l}\text { Settling } \\
\text { time 2\% }\end{array}$ & \multicolumn{2}{|l|}{ Harmonic integral } \\
\hline & $\begin{array}{l}\text { 3-phase } \\
\text { fault }\end{array}$ & $\begin{array}{l}\text { 3-phase } \\
\text { fault }\end{array}$ & $\begin{array}{l}\text { 2-phase } \\
\text { fault }\end{array}$ \\
\hline None & $0.127 \mathrm{~s}$ & 143.2 & 75.3 \\
\hline & & & \\
\hline Anti-windup: $T_{\mathrm{t}}=T_{\mathrm{i}}$ & & & \\
\hline & & & \\
\hline $2 * \mathrm{pi} *(50 \mathrm{~Hz} \pm 3 \mathrm{~Hz}) \mathrm{rad} / \mathrm{s}$ & $0.092 \mathrm{~s}$ & 87.5 & 74.3 \\
\hline $2 * \mathrm{pi} *(50 \mathrm{~Hz} \pm 5 \mathrm{~Hz}) \mathrm{rad} / \mathrm{s}$ & $0.049 \mathrm{~s}$ & 82.6 & 74.1 \\
\hline $2 * \mathrm{pi}(50 \mathrm{~Hz} \pm 10 \mathrm{~Hz}) \mathrm{rad} / \mathrm{s}$ & $0.053 \mathrm{~s}$ & 82.5 & 74.5 \\
\hline $2 * \mathrm{pi} *(50 \mathrm{~Hz} \pm 15 \mathrm{~Hz}) \mathrm{rad} / \mathrm{s}$ & $0.057 \mathrm{~s}$ & 82.5 & 74.7 \\
\hline $2 * \mathrm{pi}{ }^{*}(50 \mathrm{~Hz} \pm 20 \mathrm{~Hz}) \mathrm{rad} / \mathrm{s}$ & $0.065 \mathrm{~s}$ & 83.6 & 75.1 \\
\hline & & & \\
\hline Anti-windup $: T_{\mathrm{t}}=T_{\mathrm{i}} / 2$ & & & \\
\hline & & & \\
\hline $2 * \mathrm{pi} *(50 \mathrm{~Hz} \pm 3 \mathrm{~Hz}) \mathrm{rad} / \mathrm{s}$ & $0.114 \mathrm{~s}$ & 88.7 & 74.4 \\
\hline $2 * \mathrm{pi} *(50 \mathrm{~Hz} \pm 5 \mathrm{~Hz}) \mathrm{rad} / \mathrm{s}$ & $0.053 \mathrm{~s}$ & 82.7 & 74.6 \\
\hline $2 * \mathrm{pi} *(50 \mathrm{~Hz} \pm 10 \mathrm{~Hz}) \mathrm{rad} / \mathrm{s}$ & $0.054 \mathrm{~s}$ & 83.2 & 74.9 \\
\hline $2 * \mathrm{pi} *(50 \mathrm{~Hz} \pm 15 \mathrm{~Hz}) \mathrm{rad} / \mathrm{s}$ & $0.056 \mathrm{~s}$ & 83.4 & 75 \\
\hline $2 * \mathrm{pi} *(50 \mathrm{~Hz} \pm 20 \mathrm{~Hz}) \mathrm{rad} / \mathrm{s}$ & $0.063 \mathrm{~s}$ & 84.1 & 75.1 \\
\hline
\end{tabular}

The simulation results presented in Table III shows that if the frequency limitation is too strict the settling time increases because the frequency limitation decreases the operational range of the loop filter. It should be noted that frequency limits should never be chosen stricter than the detection frequency range of the WT loss of mains protection. Typical frequency limits for loss-of mains protection are around of 50 or $60(+1 \ldots-3) \mathrm{Hz}$ depending on the grid where the WT is connected. [12] The settling time also increases if the frequency limits are set very loose. The amount of undesirable harmonics of the converter current also increases if the limits are set too strict or loose. When 2-phase fault is subjected to the fault point 2 , the impact of frequency limitation and antiwindup decreases.

As shown in Table III the response in terms of settling time and current distortion is better when the tracking 
time is selected to $T_{\mathrm{t}}=T_{\mathrm{i}}$ instead of $T_{\mathrm{t}}=T_{\mathrm{i}} / 2$. Based on the results collected to Table III reasonable selection of frequency limitation is $2 * \mathrm{pi}^{*}(50 \mathrm{~Hz} \pm 10 \mathrm{~Hz}) \mathrm{rad} / \mathrm{s}$ with antiwindup tracking time of $T_{\mathrm{t}}=T_{\mathrm{i}}$.

The same fault as presented in section 4B is now simulated with using above selected frequency limitation and antiwindup tracking time constant. The connection point voltages are shown in Fig. 9a. The integrator anti-windup prevents the integrator output to have a large value as shown in Fig. 9b and the angular speed remains bounded due to the frequency limitation as illustrated in shown in Fig. 9c. Thus, the DDSRF-PLL angle follows the connection point voltage angle with the exception that the phase angle jumps are filtered to a large extent as depicted in Fig. 9d. The converter currents are shown in Fig. 9e and the WT successfully rides through the fault without additional stress to the grid components.

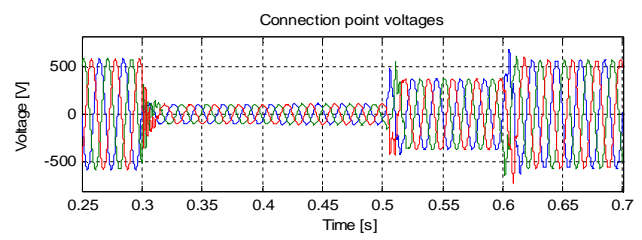

Fig. 9. a) Connection point voltages.

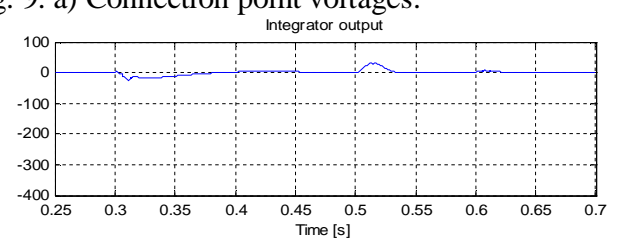

Fig. 9. b) Output of the loop filter integrator.

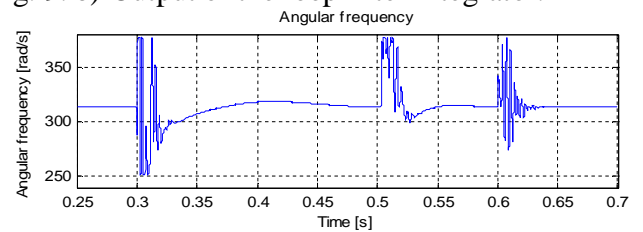

Fig. 9. c) Angular frequency of the DDSRF-PLL.

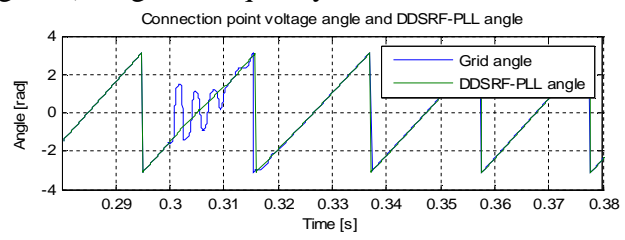

Fig. 9. d) Connection point and DDSRF-PLL angle.

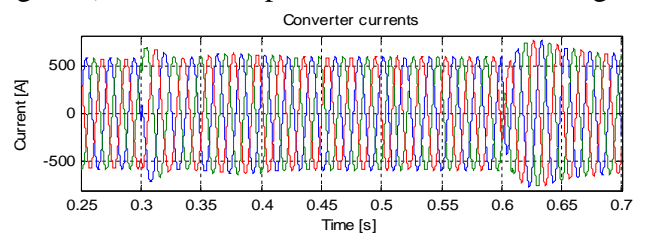

Fig. 9. e) Converter currents.

\section{Conclusion}

In this paper, the performance of wind turbine synchronizing method DDSRF-PLL during grid fault is studied. The contribution of the paper is to show that if the DDSRF-PLL proposed in many papers is used the control system of NSC may become unstable during a symmetrical grid fault. The instability problem appears only when certain tuning parameters of DDSRF-PLL are used and the fault current path is weak. Thus, the problem may not be detected. This paper proposes that it is mandatory to use PI-controller with integrator anti-windup in the loop filter of DDSRF-PLL. In addition, the impact of angular frequency limitation range on the fault ride through performance is evaluated with comparative simulations.

\section{Acknowledgement}

This work has been supported by Fortum Foundation and the Finnish Funding Agency for Technology and Innovation (TEKES) through project Smart Grid and Energy Markets (SGEM).

\section{References}

[1] WWEA (World Wind Energy Association) Website. June 2012. Available: http://www.wwindea.org/home/index.php.

[2] T. Ackermann, Wind power in power systems, John Wiley \& Sons, Ltd, Royal Institute of Technology, Stockholm, Sweden, 2005.

[3] P. Rodriquez, J. Pou, J. Bergas, J. I. Candela, R. P. Burgos, D, Boroyevich, "Decoupled double synchronous reference frame PLL for power converters control", IEEE Transactions on Power Electronics, Vol. 22, No. 2, March 2007, pp. 548-592.

[4] A. Luna, C. Citro, C. Gavriluta, J. Hermoso, I. Candela, P. Rodriquez, "Advanced PLL structures for grid synchronization in distributed generation", International Conference on Renewable Energies and Power Quality (ICREPQ'12), March 2012, pp. 10.

[5] R. Teodorescu, M. Liserre, P. Rodriquez, Grid converters for photovoltaic and wind power systems, John Wiley \& Sons, Ltd, West Sussex, United Kingdom, 2011, 398 p.

[6] S. Gao, M. Barnes, "Phase-locked loop for AC systems: Analyses and comparisons", $6^{\text {th }}$ International Conference on Power Electronics and Drives, March 2012, 6p.

[7] V. Kaura, V. Blasko, "Operation of a phase locked loop system under distorted utility conditions", IEEE Transactions on Industry Applications, Vol. 33, No. 1, 1997, pp. 58-63.

[8] S. K. Chung, "A phase tracking system for three phase utility interface inverters", IEEE Transactions on Power Electronics, Vol. 15, No. 3, May 2000, pp. 431-438.

[9] K. J. Åström, T. Hägglund, Advanced PID control, ISA Instrumentation, Systems and Automation Society, Research Triangle Park, North Carolina, USA, 2006, 460p.

[10] M. Liserre, F. Blaabjerg, S. Hansen, "Design and control of an LCL-filter-based three-phase active rectifier", IEEE Transactions on Industry Applications, Vol. 41, No. 5 , 2005, pp. 1281-1291.

[11] P. M. Anderson, Power system protection. IEEE Press in association with McGraw-Hill, 1999, 1307p.

[12] V. V. Thong, R. Belmans, "Maximum penetration level of distributed generation with safety criteria", European Transactions on Electrical Power, 2010, pp. 367-381. 